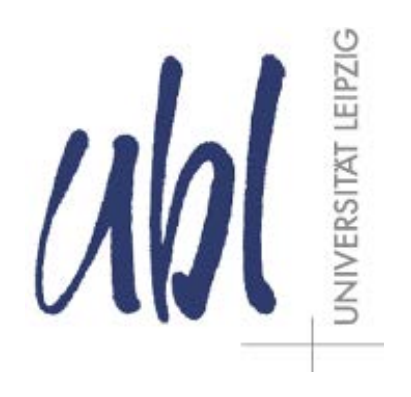

Institute of Medical Physics and Biophysics

Medical Department, Leipzig University

Author Manuscript

(C) 2015. This manuscript version is made available under the CC-BY-NC-ND 4.0 license

http://creativecommons.org/licenses/by-nc-nd/4.0/

Published in final edited form as:

Free Radical Research, 2015 Jun; 49:768-76.

Available at:

http://dx.doi.org/10.3109/10715762.2014.999676.

\title{
DETECTION OF THE HALOGENATING ACTIVITY OF HEME PEROXIDASES IN LEUKOCYTES BY AMINOPHENYL FLUORESCEIN
}

\author{
Jörg Flemmig, Johannes Remmler, Josefin Zschaler \& Jürgen Arnhold \\ Institute for Medical Physics and Biophysics, Medical Faculty, Leipzig University, \\ Leipzig, Germany
}

\begin{abstract}
The formation of hypochlorous and hypobromous acids by heme peroxidases is a key property of certain immune cells. These products are not only involved in defense against pathogenic microorganisms and in regulation of inflammatory processes, but contribute also to tissue damage in certain pathologies. After a short introduction about experimental approaches for the assessment of the halogenating activity in vitro and in cell suspensions, we are focusing on novel applications of fluorescent dye systems to detect the formation of hypochlorous acid $(\mathrm{HOCl})$ in leukocytes. Special attention is directed to properties and applications of the non-fluorescent dye aminophenyl fluorescein that is converted by $\mathrm{HOCl}$, $\mathrm{HOBr}$, and other strong oxidants to fluorescein. This dye allows the detection of the halogenating activity in samples containing free myeloperoxidase and eosinophil peroxidase as well as in intact granulocytes using fluorescence spectroscopy and flow cytometry, respectively.
\end{abstract}

\section{Abbreviations:}

APF, aminophenyl fluorescein; DCF, 2,7-dichlorofluorescein diacetate; DTNB, 5,5'dithiobis(2-nitrobenzoicacid); EGCG, (-)-epigallocatechin-3-gallate; EPO, eosinophil peroxidase; FRET, fluorescence resonance energy transfer; HE, hydroethidine; HPF, hydroxyphenyl fluorescein; LPO, lactoperoxidase; MDM, monochlorodimedon; MPO, myeloperoxidase; NADPH, nicotinamide adenine dinucleotide phosphate; Por, porphyrin; ROS, reactive oxygen species; SNAPF, sulfonaphthoaminophenyl fluorescein; TNB, 5-thio-2nitrobenzoic acid 


\section{Keywords:}

myeloperoxidase, hypochlorous acid, neutrophils, aminophenyl fluorescein, eosinophil peroxidase, hypobromous acid, eosinophils

\section{Introduction}

Human immune cells express several heme peroxidases that are able to oxidize (pseudo)halides to their corresponding (pseudo)hypohalous acids. These products are involved in specific functions such as killing of pathogenic microorganisms and regulation of immune responses, but can also contribute to tissue damage in certain pathologies. Thus, the specific quantification of the halogenating activity of these enzymes is of high scientific and medical interest. There are several approaches for measuring the halogenating activity of isolated heme peroxidases under in vitro conditions. However, it is still a challenge to deter- mine this enzymatic activity inside their hosting cells under ex vivo conditions in cell suspensions.

Here, we give a short overview about halide oxidation by heme peroxidases and methods applied for the detection of the corresponding products in cells. In the second part of this review, we will focus on the properties and application of aminophenyl fluorescein (APF) that considerably improved the detection of hypochlorous $(\mathrm{HOCl})$ and hypobromous $(\mathrm{HOBr})$ acids in stimulated leukocytes.

\section{Halide oxidation by heme peroxidases}

\section{Human heme peroxidases}

In mammals, the heme proteins myeloperoxidase (MPO) and eosinophil peroxidase (EPO) are the only enzymes known to be able to oxidize $\mathrm{Cl}^{-}$to $\mathrm{HOCl}$ and $\mathrm{Br}^{-}$to $\mathrm{HOBr}$ [1-3]. The ability of EPO to oxidize $\mathrm{Cl}^{-}$is restricted to acidic $\mathrm{pH}$ values $[3,4]$. Both enzymes are also known to oxidize $\mathrm{I}^{-}$and $\mathrm{SCN}^{-}[2,3]$. Taking into account physiologic (pseudo)halide concentrations in blood, their known reaction rates with activated peroxidases, and assuming neutral $\mathrm{pH}$ values, MPO oxidizes mainly $\mathrm{Cl}^{-}$and $\mathrm{SCN}$, whereas EPO uses presumably $\mathrm{Br}^{-}$and $\mathrm{SCN}^{-}$as substrates $[5,6]$. Oxidation of iodide by MPO and EPO is of little importance due to the low iodide concentration $(<1 \mu \mathrm{M}$ [7]) in blood and tissues with the exception of thyroid gland.

MPO is mostly found in neutrophils and to a lesser extent in monocytes. Both cell types play an important role in early activation of host response to pathogenic microorganisms, trauma, and other disturbances of normal homeostasis. MPO contributes to pathogen inactivation, regulation of the inflammatory process, and also to tissue injury [8]. Eosinophil granulocytes contain EPO that has been implicated not only in protecting against helminthic parasites but also in promoting tissue damage in asthma and other diseases $[9,10]$.

A related heme peroxidase is lactoperoxidase (LPO) found in external secretions such as saliva, tears, milk, and bronchial secretions [11]. This enzyme has protective functions at mucous surfaces and in secretions by oxidizing $\mathrm{SCN}^{-}$to hypothiocyanite ${ }^{-} \mathrm{OSCN}$. LPO is also able to use $\mathrm{I}^{-}$as substrate, but not $\mathrm{Cl}^{-}$or $\mathrm{Br}^{-}[12]$. 


\section{Halogenation and peroxidase cycles}

To induce the (pseudo)halogenating activity, all the mentioned heme peroxidases need to be activated by hydrogen peroxide [13]. During this interconversion (Figure 1, Reaction 1), the ferric heme (Por- $\mathrm{Fe}^{3+}$; Por denotes the porphyrin ring) group is oxidized to an oxo-ferryl species ( ${ }^{\circ+}$ Por- $\mathrm{Fe}^{4+}=0$ ) additionally bearing a cation radical function at the Por ring. This intermediate is known as compound I in peroxidase chemistry [14]. During (pseudo)halide oxidation, compound $\mathrm{I}$ is reduced in a two-electron step to the ferric enzyme form (Figure 1, Reaction 2) $[15,16]$. Reactions 1 and 2 comprise the so-called "halogenation cycle". Alternatively, compound I can be reduced to the ferric enzyme form by two consecutive one-electron processes via compound II (Por- $\left.-\mathrm{Fe}^{4+}-\mathrm{OH}\right)$, having the heme iron in the oxo-ferryl state but lacking an additional radical function (Figure 1, Reactions 3 and 4). In these reactions different small substrates including tyrosine, tryptophan, nitrite, hydrogen peroxide, xenobiotics, and others will be oxidized by abstracting one electron under formation of substrate radicals [17-21]. Reactions 1,3 , and 4 comprise the peroxidase cycle.

\section{Redox properties of hypohalous acids and hypothiocyanite}

The hypohalous acids $\mathrm{HOCl}$ and $\mathrm{HOBr}$ are powerful two-electron oxidants. Their standard reduction potentials at $\mathrm{pH} 7\left(E^{\circ}\right)$ and other key properties are listed in Table I. The indicated standard reduction potentials at $\mathrm{pH} 7$ for $\mathrm{HOCl}$ and $\mathrm{HOBr}$ increase with decreasing $\mathrm{pH}$ by $0.0295 \mathrm{~V}$ per decreasing $\mathrm{pH}$ unit as two electrons and one proton will be transferred during their reduction to the halide ion [4]. The corresponding half reactions for these reductions are

$$
\begin{aligned}
& \mathrm{HOCl}+2 \mathrm{e}^{-}+\mathrm{H}^{+} \longrightarrow \mathrm{Cl}^{-}+\mathrm{H}_{2} \mathrm{O} \text { and } \\
& \mathrm{HOBr}+2 \mathrm{e}^{-}+\mathrm{H}^{+} \longrightarrow \mathrm{Br}^{-}+\mathrm{H}_{2} \mathrm{O}
\end{aligned}
$$

In case of hypothiocyanite, the corresponding half reaction is at slightly acidic and neutral $\mathrm{pH}$ values:

$$
\mathrm{OSCN}+2 \mathrm{e}^{-}+2 \mathrm{H}^{+} \longrightarrow \mathrm{SCN}^{-}+\mathrm{H}_{2} \mathrm{O}
$$

The standard reduction potential for the couple ${ }^{-} \mathrm{OSCN} / \mathrm{SCN}^{-}, \mathrm{H}_{2} \mathrm{O}$ increases with decreasing $\mathrm{pH}$ by $0.059 \mathrm{~V}$ per decreasing $\mathrm{pH}$ unit.

Both $\mathrm{HOCl}$ and $\mathrm{HOBr}$ are powerful agents that oxidize numerous amino acids and other small molecules [26-28]. Hypothiocyanite is a much weaker oxidant as reflected by its lower standard reduction potential (Table I). It oxidizes presumably thiol and selenol residues $[29,30]$.

\section{Substrates suitable for detecting the formation of $\mathrm{HOCl} / \mathrm{HOBr}$ in vitro and in leukocytes}

\section{Detection of hypohalous acids in biological samples}

Several approaches have been developed to measure and quantify the formation of $\mathrm{HOCl}$ under in vitro conditions in peroxidase samples or crude enzyme preparations. An overview about common substrates used for the detection of $\mathrm{HOCl}$ and also $\mathrm{HOBr}$ is given in Table II.

Taurine reacts with $\mathrm{HOCl}$ to taurine chloramine that can be assayed either by $3,3^{\prime}, 5,5^{\prime}$ tetramethylbenzidine, dihydrorhodamine, or 5-thio-2-nitrobenzoic acid (TNB) [48]. In the 
presence of MPO, taurine interacts with the reversible high-spin complex between MPO compound I and chloride under formation of taurine chloramine and ferric MPO $[49,50]$. This enables taurine to detect the chlorinating activity of MPO at $\mathrm{pH}$ 7.4. Other methods for the detection of $\mathrm{HOCl}$ production by MPO, like the application of MDM or unsaturated phosphatidylcholines, measured a lower chlorinating activity at $\mathrm{pH} 7.4$ [31] or worked only at more acidic $\mathrm{pH}$ values $[4,45,51]$. Moreover, $\mathrm{HOBr}$ is better detectable than $\mathrm{HOCl}$ at neutral $\mathrm{pH}$ values [32,52]. A differentiation between the formation of $\mathrm{HOCl}$ and $\mathrm{HOBr}$ has been described applying taurine in combination with 3,3',5,5'-tetramethylbenzidine and iodide [32]. Otherwise, applying mass spectrometric approaches, the formation of these hypohalous acids can also be distinguished using tyrosine [36] or unsaturated phosphatidylcholines $[46,47]$ as target.

Among the methods listed in Table II, only applications of monochlorodimedon (MDM) and TNB enable the continuous monitoring of hypohalous acid formation. However, the TNB assay is highly unspecific $[40,41]$ and should only be applied when interferences with other reactive species are ruled out.

\section{Unspecific approaches for detection of halogenating activity in leukocytes}

The activation of neutrophils is highly associated with the production of reactive oxygen species (ROS) due to reactions mainly driven by nicotinamide adenine dinucleotide phosphate (NADPH) oxidase and MPO. In suspensions of these cells, the involvement of MPO metabolites in generation of time-dependent chemiluminescence signals (using luminol [53-55] or pholasin [56]) can be assessed by MPO inhibitors and also in case of MPO release from cells by $\mathrm{HOCl}$ scavengers. Unfortunately, these approaches allow only the detection of summary effects concerning the whole cell suspension.

Data about oxidant generation based on the analysis of numerous single cells can be obtained via flow cytometry by applying appropriate cell-permeable dyes that change their fluorescent properties upon interaction with ROS. Among them are the non-fluorescent 2,7-dichlorofluorescein diacetate (DCF) and dihydrorhodamine 123 that are converted upon interaction with $\mathrm{HOCl}$ or other ROS into a fluorescent species $[57,58]$. In addition to $\mathrm{HOCl}$, DCF responds also to numerous other oxidants such as hydroxyl radicals, peroxynitrite, nitric oxide, as well as hydrogen peroxide in the presence of peroxidases [59]. Applying DCF, an increased ROS production was detected in mice microglial cells after inhibition of MPO as well as in microglial cells from MPO-deficient mice [60]. Dihydrorhodamine 123 is oxidized by $\mathrm{HOCl}$, peroxynitrite, iron-mediated processes, and hydrogen peroxide in the presence of peroxidases [59]. Signals of this dye were strongly reduced in neutrophils from patients with complete MPO deficiency [61].

\section{Development of more specific methods for chlorinating activity in leukocytes}

During the last years, several cell-permeable substrates have been introduced that interact more specifically with $\mathrm{HOCl}$ without any interfering activation by superoxide anion radicals or hydrogen peroxide. These approaches enable the specific study of MPO-driven reactions in single neutrophils by means of flow cytometry. An overview about these novel fluorescence-based $\mathrm{HOCl}$-specific detection systems is given in Table III.

In most cases, non-fluorescent dyes are converted upon interaction with $\mathrm{HOCl}$ or applying the MPO-hydrogen peroxide-chloride system into a fluorescent species [62-70]. This has been achieved by introduction of specific reactive groups into fluorophores whereby the parent molecule lost its ability to fluoresce. Selected structures for these molecules with 
emphasis on the reactive site are given in Figure 2. In these dyes, fluorescence quenching is overcome either by cleavage of a $p$-aminophenyl moiety $[62,63]$ or by oxidation of a functional residue [64,65]. Two examples for non-fluorescent spirocyclic rhodamine derivatives are also shown in Figure 2. Hypochlorous acid induces, via ring opening and oxidative conversions, the formation of highly fluorescent rhodamines [66-70].

Another principle is realized in $\mathrm{HOCl}$-sensitive fluorescent quantum dots, where $\mathrm{HOCl}$ induces a fluorescence quenching [72]. A further $\mathrm{HOCl}$ detection mechanism is used in rhodamine-thiosemicarbazide-derived probes bearing an additional coumarin subunit. Upon excitation of the coumarin moiety, a fluorescence resonance energy transfer (FRET) takes place only at the rhodamine subunit when the thiosemicarbazide part has been modified by $\mathrm{HOCl}[71]$.

Concerning $\mathrm{HOCl}$-induced conversions of these detection systems, only the structures of the target and the resulting final molecule are reported. However, there is a lack of detailed reaction mechanisms of these dyes with $\mathrm{HOCl}$. In most cases, authors claimed that their detection system is highly specific for $\mathrm{HOCl}$ by comparing the fluorescence response to $\mathrm{HOCl}$ with other oxidants. However, $\mathrm{HOBr}$ was not included in these test systems. Interferences with other oxidants are reported for APF [62] (see also below). In case of the $\mathrm{HKOCl}-1$ system, a small interference with peroxynitrite was found [64].

Although the applicability of $\mathrm{HOCl}$-sensitive probes has been demonstrated on selected examples for determination of chlorinating activity in leukocytes and biological imaging, further systematic investigations of their properties are mandatory for future applications.

\section{Properties of the APF/HPF system}

\section{Activation of APF and HPF by strong oxidants}

The dye 2-[6-(4'-amino)phenoxy-3H-xanthen-3-on-9-yl)benzoic acid or, as shortly named "APF", is among the substrates applied for measuring the chlorinating activity in leukocytes [62]. In this non-fluorescent molecule, an aminophenyl moiety is covalently attached to fluorescein (Figure 3). The properties of APF and examples for application are reviewed in the next paragraphs.

Together with APF a related dye, namely 2-[6-(4'-hydroxy)phenoxy-3H-xanthen-3-on-9yl)benzoic acid (shortly called "hydroxyphenyl fluorescein" or "HPF"), was introduced [62]. In contrast to APF, HPF bears a hydroxyl group instead of an amino group on the phenyl residue attached to the $6^{\prime}$-position of fluorescein. Both non-fluorescent fluorescein derivatives are converted into fluorescein upon reaction with strong oxidants such as hydroxyl radicals (generated by a Fenton system) or peroxynitrite. It has been shown that their fluorescence is not activated by singlet oxygen, superoxide anion radicals, hydrogen peroxide, nitric oxide, peroxyl radicals, or light-induced autoxidation [62]. In another study, however, an increasing fluorescence signal derived from APF was reported in the presence of singlet oxygen, while HPF was less sensitive against this oxidant [73].

Interaction of $\mathrm{HOCl}$ with APF, but not with HPF, also yielded a fluorescent species. Thus, by comparing the fluorescence answers in neutrophils in the presence of APF or HPF, it is possible to evaluate the specific response to $\mathrm{HOCl}$ [62]. Hypobromous acid also converts APF (but not HPF) into a fluorescent species $[74,75]$. This approach allows the detection of the brominating activity in eosinophils [75]. In order to relate APF-derived signals in 
biological samples to the formation of hypohalous acids and to exclude effects of other strong oxidants, the application of peroxidase inhibitors is mandatory.

Preliminary data suggest that APF is also oxidized by MPO compounds I and II with rates of $6.5 \times 10^{5} \mathrm{M}^{-1} \mathrm{~s}^{-1}$ and $2.5 \times 10^{4} \mathrm{M}^{-1} \mathrm{~s}^{-1}$, respectively, at $25{ }^{\circ} \mathrm{C}$ and $\mathrm{pH} 7$ [unpublished data]. Considering the marked difference between concentrations of chloride (around $0.1 \mathrm{M}$ ) and, if applied, APF (only few $\mu \mathrm{M}$ ) and the rate of MPO compound I with chloride being $2.5 \times 10^{4}$ $\mathrm{M}^{-1} \mathrm{~s}^{-1}$ at $15{ }^{\circ} \mathrm{C}$ and $\mathrm{pH} 7$ [2], conditions are expected in neutrophil samples favoring a priority oxidation of chloride instead of APF by compound I of MPO.

\section{Mechanistic details of fluorescence dequenching in APF and HPF}

The activation of APF and HPF includes the cleavage of the aryloxyphenol group from the xanthene moiety of these molecules by highly reactive oxidants, resulting in the release of fluorescein that is well known for its intense fluorescence [62]. In APF and HPF, a benzene unit in the form of a $p$-benzoquinone monoamine (APF) or a $p$-benzoquinone hydroxyl moiety (HPF) is covalently attached to the core xanthene moiety at the 6'-position of fluorescein. In fluorescein derivatives, fluorescence is controlled by photo-induced intramolecular electron transfer processes. A fluorescence quenching might result by electron transfer between different molecule parts in dependence on redox properties of these substructures [76-79]. In APF and HPF, strong oxidants overcome this quenching by release of the electron-rich benzoquinone moiety from the $6^{\prime}$-position of fluorescein. This initial reaction is assumed to start by abstraction of a hydrogen atom from the phenolic hydroxyl group in HPF or from the aminogroup in APF [62]. This mechanism is apparently valid for the action of strong oxidants like hydroxyl radicals and peroxynitrite but unlikely for hypohalous acids. Apparently, $\mathrm{HOCl}$ acts on APF via the formation of an intermediate chloramine on the $p$-benzoquinone monoamine group and subsequent abstraction of the benzene moiety. A similar mechanism should be valid for $\mathrm{HOBr}$. Hypochlorous acid is well known for its ability to form $N$-chloramines with substrates bearing amino groups [80-82].

The formation of fluorescein upon interaction of hypohalous acids with APF was confirmed by matrix-assisted laser desorption/ionization time-of-flight mass spectrometry. Mono- and dichlorinated products as well as mono- and dibrominated products of fluorescein were found after incubation of APF with increasing amounts of hypohalous acids [75]. Comparable experiments with HPF primarily resulted in chlorinated and brominated products of the dye without the formation of fluorescein [75]. To overcome additional halogenations of resulting fluorescein, APF should be used in excess over $\mathrm{HOCl} / \mathrm{HOBr}$.

\section{Selected examples for the application of APF}

\section{Detection of the halogenating activity of MPO and EPO}

Using APF, the in vitro halogenating activity of both MPO and EPO can be easily followed after enzyme activation by hydrogen peroxide by monitoring the fluorescence increase around $525 \mathrm{~nm}$ due to the formation of fluorescein [75]. At pH 7.4, the increase of fluorescence in the MPO-hydrogen peroxide system depended highly on the presence of chloride ions. However, the sole application of $\mathrm{Br}^{-}$to MPO caused a much slower and less pronounced increase in the fluorescence [75]. The MPO inhibitor 4-aminobenzoic acid hydrazide totally abolished any halogenating activity of MPO.

The concentration-dependent inactivation of MPO by chlorite was associated with a decrease in APF fluorescence [83]. 
Halide oxidation by the EPO-hydrogen peroxide system can also be followed by APF. Here, bromide induced a much stronger and faster response than chloride. Interestingly, the application of both bromide (at $100 \mu \mathrm{M}$ ) and chloride (at $100 \mathrm{mM}$ ) showed a cooperative effect in this investigation leading to a faster increase in APF destruction than in the sole presence of bromide [75]. The sole addition of $\mathrm{SCN}^{-}$to the MPO/EPO-hydrogen peroxide system did not induce a fluorescence increase in the presence of APF indicating the inability of ${ }^{-}$OSCN to react with APF [75].

The APF/HPF system was also applied for measuring the halogenating activity of MPO in murine tissue and organ samples, whereby the MPO activity in extra- and intracellular protein fractions were separately measured [84]. All investigated tissue homogenates contained substances that inhibited the APF/HPF-derived fluorescence. An increased APFderived fluorescence versus control was only found in the extracellular protein fraction of spleen and lung tissue. These authors raised considerable doubt on the specificity of the APF/HPF method and other applied MPO assays for correct measurements of MPO activity in biological samples as interfering substances like other peroxidases, hemoglobin, myoglobin, and tissue inhibitors may disturb the results. Moreover, poor specificity of the APF/HPF system was also demonstrated comparing MPO activity in wild-type and MPO -knockout mice. To improve the measurement of MPO activity in biological samples, they proposed the previous capture of MPO by a specific antibody [84].

\section{Detection of the formation of $\mathrm{HOCl}$ by other enzymes}

APF was successfully applied to demonstrate the transient formation of $\mathrm{HOCl}$ during irreversible inactivation of prokaryotic chlorite dismutase [85]. This heme $b$-dependent oxidoreductase converts chlorite into chloride and dioxygen [86].

\section{Applications of APF to isolated neutrophils and eosinophils}

Phorbol ester-stimulated porcine neutrophils increase their fluorescence in the presence of APF, but not HPF, as shown by bioimaging of the cells [62]. We applied flow cytometry analysis for measuring APF-mediated fluorescence in human phorbol ester-stimulated neutrophil and eosinophil samples. In these cell types, the peroxidase inhibitor 4-aminobenzoic acid hydrazide and the NADPH-oxidase inhibitor diphenyleneiodonium chloride abolished the APF-induced fluorescence, while the inducible nitric oxide synthase inhibitor $N^{G}$-monomethyl L-arginine was ineffective [75]. In human neutrophils treated with hydrogen peroxide, the modulating effect of the dietary flavonoid (-)-epicatechin on the APF response was also investigated. (-)-Epicatechin enhanced the chlorinating activity by overcoming the hydrogen peroxide-mediated accumulation of inactive compound II of MPO [87].

The APF approach can also be applied for detecting peroxidase-containing cell populations in diluted human and rodent blood samples by flow cytometry after depletion of red blood cells by hypotonic lysis [88]. In this study, the mixed leukocyte-enriched cell fraction was incubated with APF and $\mathrm{H}_{2} \mathrm{O}_{2}$. Peroxidase-containing cell fractions, such as neutrophils, eosinophils, and monocytes, were identified by antibodies against CD16, CCR3, and CD14, respectively, and related to scattering parameters of these cells [88]. In future, this approach might allow the screening of peroxidase-deficiency in blood samples by measuring the halogenating activity. Until now, only the peroxidase activity could be addressed during blood analysis [89,90]. Using this approach, factors affecting the halogenating activity of leukocytes in blood samples can be also systematically investigated. 


\section{Applications of APF/HPF to leukemic cells}

MPO-transfected leukemia K562 cells markedly increased their ROS formation in the presence of (-)-epigallocatechin-3-gallate (EGCG) as visualized by increased values for APFand HPF-induced fluorescence [91]. The $\mathrm{As}_{2} \mathrm{O}_{3}$-mediated apoptosis of $\mathrm{HL}-60$ cells, which are known to contain MPO, was also enhanced by EGCG, whereby the degree of apoptosis correlated with ROS formation [91]. Authors concluded that MPO activity and the enhanced formation of hydroxyl radicals are responsible for these effects. As (-)-epicatechin and their derivatives are able to significantly enhance the chlorinating activity of MPO [34,87], these data underline the cytotoxic role of MPO-derived oxidants.

\section{Conclusions}

APF is a suitable tool for assessment of the formation of hypohalous acids and other strong oxidants in biological samples. Especially, the halogenating activities of MPO in neutrophils and EPO in eosinophils can be measured by APF using flow cytometry. The application of peroxidase inhibitors is mandatory in control measurements to exclude any potential interference from other strong oxidants. The discrimination between the formation of $\mathrm{HOCl}$ and $\mathrm{HOBr}$ as well as between the contribution of neutrophils and eosinophils by means of APF fluorescence remains challenging.

\section{Declaration of interest}

The authors report no declarations of interest. The authors alone are responsible for the content and writing of the paper.

The authors gratefully acknowledge the financial support provided by the Sächsische Aufbaubank from a funding of the European Regional Development Fund (ERDF) (SAB Project Nr: 100116526) and the German Federal Ministry of Education and Research (BMBF 1315883). 


\section{References}

[1] Bakkenist ARJ, de Boer JEG, Plat $\mathrm{H}$, Wever R. The halide complexes of myeloperoxidase and the mechanism of the halogenation reactions. Biochim Biophys Acta 1980;613:337-348.

[2] Furtmüller PG, Burner U, Obinger C. Reaction of myeloperoxidase compound I with chloride, bromide, iodide and thiocyanate. Biochemistry 1998;37:17923-17930.

[3] Furtmüller PG, Burner U, Regelsberger G, Obinger C. Spectral and kinetic studies on the formation of eosinophil peroxidase compound I and its reaction with halides and thiocyanate. Biochemistry 1998;37:17923-17930.

[4] Spalteholz H, Panasenko OM, Arnhold J. Formation of reactive halide species by myeloperoxidase and eosinophil peroxidase. Arch Biochem Biophys 2006;445:225-234.

[5] van Dalen CJ, Whitehouse MW, Winterbourn CC, Kettle AJ. Thiocyanate and chloride as competing substrates for myeloperoxidase. Biochem J 1997;327:487-492.

[6] van Dalen CJ, Kettle AJ. Substrates and products of eosinophil peroxidase. Biochem J 2001;358:233-239.

[7] Holzbecher J, Ryan DE. The rapid determination of total bromine and iodine in biological fluids by neutron activation. Clin Biochem 1980;13:277-278.

[8] Arnhold J, Flemmig J. Human myeloperoxidase in innate and acquired immunity. Arch Biochem Biophys 2010;500:92-106.

[9] Bousquet J, Chanez P, Lacoste JY, Barneon G, Ghavanian N, Enander I et al. Eosinophilic inflammation in asthma. New Engl J Med 1990;323:1033-1039.

[10] Shamri R, Xenakis JJ, Spencer LA. Eosinophils in innate immunity: an evolving story. Cell Tissue Res 2011;343:57-83.

[11] Thomas EL, Bozeman PM, Learn DB. Lactoperoxidase: Structure and catalytic properties. In: Everse J, Everse KE, Grisham MB (eds). Peroxidases in Chemistry and Biology. Boca Raton: CRC Press; 1991:123-142.

[12] Furtmüller PG, Jantschko W, Regelsberger G, Jakopitsch C, Arnhold J, Obinger C. Reaction of lactoperoxidase compound I with halides and thiocyanate. Biochemistry 2002;41:11895-11900.

[13] Furtmüller PG, Zederbauer M, Jantschko W, Helm J, Bogner M, Jakopitsch C, et al., Active site structure and catalytic mechanisms of human peroxidases. Arch Biochem Biophys 2006;445:199213.

[14] Dolphin D, Forman A, Borg DC, Fajer J, Felton RH. Compounds I of catalase and horseradish peroxidase: $\pi$-cation radicals. Proc Nat Acad Sci USA 1971;68:614-618.

[15] Klebanoff SJ. Myeloperoxidase: occurrence and biological function. In: Everse J, Everse KE, Grisham MB (eds). Peroxidases in Chemistry and Biology. Boca Raton: CRC Press; 1991:1-35.

[16] Harrison JE, Schultz J. Studies on the chlorinating activity of myeloperoxidase. J Biol Chem 1976;251:1371-1374.

[17] Marquez LA, Dunford HB. Kinetics of oxidation of tyrosine and dityrosine by myeloperoxidase compounds I and II. J Biol Chem 1995;270:30434-30440.

[18] Burner U, Jantschko W, Obinger C. Kinetics of oxidation of aliphatic and aromatic thiols by myeloperoxidase compounds I and II. FEBS Lett 1999;443:290-296.

[19] Burner U, Furtmüller PG, Kettle AJ, Koppenol WH, Obinger C. Mechanism of myeloperoxidase with nitrite. J Biol Chem 2000;275:20597-20601. 
[20] Furtmüller PG, Burner U, Jantschko W, Regelsberger G, Obinger C. Two-electron reduction and one-electron oxidation of organic hydroperoxides by human myeloperoxidase. FEBS Lett 2000;484:139-143.

[21] Jantschko W, Furtmüller PG, Allegra M, Livrea MA, Jakopitsch C, Regelsberger G, et al. Redox intermediates of plant and mammalian peroxidases: a comparative transient-kinetic study of their reactivity toward indole derivatives. Arch Biochem Biophys 2002;398:12-22.

[22] Arnhold J, Monzani E, Furtmüller PG, Zederbauer M, Casella L, Obinger C. Kinetics and thermodynamics of halide and nitrite oxidation by mammalian heme peroxidases. Eur J Inorg Chem 2006:3801-3811.

[23] Morris JC. The acid ionization constant of $\mathrm{HOCl}$ from 5 to $35^{\circ}$. J Phys Chem 1966;70:37983805.

[24] Troy RC, Margerum DW. Non-metal redox kinetics: hypobromite and hypobromous acid reactions with iodide and with sulfite and the hydrolysis of bromosulfate. Inorg Chem 1991;30:35383543.

[25] Thomas EL. Lactoperoxidase-catalyzed oxidation of thiocyanate: equilibria between oxidized forms of thiocyanate. Biochemistry 1981;20:3273-3280.

[26] Pattison DI, Davies MJ. Absolute rate constants for the reaction of hypochlorous acid with protein side chains and peptide bonds. Chem Res Toxicol 2001;14:1453-1464.

[27] Hawkins CL, Pattison DI, Davies MJ. Hypochlorite-induced oxidation of amino acids, peptides and proteins. Amino Acids 2003;25:259-274.

[28] Pattison DI, Davies MJ. Kinetic analysis of the reactions of hypobromous acid with protein components: implications for cellular damage and use of 3-bromotyrosine as a marker of oxidative stress. Biochemistry 2004;43:4799-4809.

[29] Skaff O, Pattison DI, Davies MJ. Hypothiocyanous acid reactivity with low-molecular-mass and protein thiols: absolute rate constants and assessment of biological relevance. Biochem J 2009;422:111-117.

[30] Skaff O, Pattison DI, Morgan PE, Bachana R, Jain VK, Priyadarsin KI, et al. Selenium-containing amino acids are targets for myeloperoxidase-derived hypothiocyanous acid: determination of absolute rate constants and implications for biological damage. Biochem J 2012;441:305-316.

[31] Kettle AJ, Winterbourn CC. Assays for the chlorinating activity of myeloperoxidase. Meth Enzymol 1994;233:502-512.

[32] Senthilmohan R, Kettle AJ. Bromination and chlorination reactions of myeloperoxidase at physiological concentrations of bromide and chloride. Arch Biochem Biophys 2006;445:235-244.

[33] Hager LP, Morris DR, Brown FS, Eberwein H. Chloroperoxidase. II. Utilization of halogen anions. J Biol Chem 1966;241:1769-1777.

[34] Kirchner T, Flemmig J, Furtmüller PG, Obinger C, Arnhold J. (-)-Epicatechin enhances the chlorinating activity of human myeloperoxidase. Arch Biochem Biophys 2010;495:21-27.

[35] Kettle AJ. Neutrophils convert tyrosyl residues in albumin to chlorotyrosine. FEBS Lett 1996;379:103-106.

[36] Chapman AL, Senthilmohan R, Winterbourn CC, Kettle AJ. Comparison of mono- and dichlorinated tyrosines with carbonyls of hypochlorous acid-modified proteins. Arch Biochem Biophys 2000;377:95-100. 
[37] Aldrigde RE, Chan TP, van Dalen CJ, Senthilmohan R, Town GI, Winn MC, et al. Eosinophil peroxidase produced hypobromous acid in the airways of stable asthmatics. Free Radic Biol Med 2002;33:847-856.

[38] Chien TL, de Jong J, Bast A. A method for screening hypochlorous acid scavengers by inhibition of the oxidation of 5-thio-2-nitrobenzoic acid: application to anti-asthmatic drugs. Anal Biochem 1994;218:377-381.

[39] Lloyd MM, van Reyk DM, Davies MJ, Hawkins CL. Hypothiocyanous acid is a more potent inducer of apoptosis and protein thiol depletion in murine macrophage cells than hypochlorous acid or hypobromous acid. Biochem J 2008;414:271-280.

[40] Landino LM, Mall CB, Nicklay JJ, Dutcher SK, Moynihan KL. Oxidation of 5-thio-2-nitrobenzoic acid by the biologically relevant oxidants peroxynitrite anion, hydrogen peroxide, and hypochlorous acid. Nitric Oxide 2008;18:11-18.

[41] Nagy P, Jameson GNL, Winterbourn CC. Kinetics and mechanisms of the reaction of hypothiocyanous acid with 5-thio-2-nitrobenzoic acid and glutathione. Chem Res Toxicol 2009;22:1833-1840.

[42] Maghzal GJ, Cergol KM, Shengule SR, Suarna C, Newington D, Kettle AJ, et al. Assessment of myeloperoxidase activity by the conversion of hydroethidine to 2-chloroethidium. J Biol Chem 2014;289:5580-5595.

[43] Zielonka J, Kalyanaraman B. Hydroethidine- and MitoSOXderived red fluorescence is not a reliable indicator of intracellular superoxide formation. Another inconvenient truth. Free Radic Biol Med 2010;48:983-1001.

[44] Winterbourn CC, van den Berg JJM, Roitman E, Kuypers FA. Chlorohydrin formation from unsaturated fatty acids reacted with hypochlorous acid. Arch Biochem Biophys 1992;296:547-555.

[45] Panasenko OM, Spalteholz H, Schiller J, Arnhold J. Myeloperoxidase-induced formation of chlorohydrin and lysophospholipids from unsaturated phosphatidylcholines. Free Radic Biol Med 2003;34:553-562.

[46] Spalteholz H, Wenske K, Panasenko OM, Schiller J, Arnhold J. Evaluation of products upon the reaction of hypohalous acid with unsaturated phosphatidylcholines. Chem Phys Lipids 2004;129:8596.

[47] Spalteholz H, Wenske K, Arnhold J. Interaction of hypohalous acids and heme peroxidases with unsaturated phosphatidylcholines. Biofactors 2005;24:67-76.

[48] Kettle AJ, Albrett AM, Chapman AL, Dickerhof N, Forbes LV, Khalilova I et al. Measuring chlorine bleach in biology and medicine. Biochim Biophys Acta 2014;1840:781-793.

[49] Marquez LA, Dunford HB. Chlorination of taurine by myeloperoxidase. J Biol Chem 1994;269:7950-7956.

[50] Ramos DR, Victoria Garcia M, Canle LM, Autroa Santaballa J, Furtmüller PG, Obinger C. Myeloperoxidase-catalyzed taurine chlorination: initial versus equilibrium rate. Arch Biochem Biophys 2007;466:221-233.

[51] Jerlich A, Horakova L, Fabjan JS, Giessauf A, Jürgens G, Schaur RJ. Correlation of low-density lipoprotein modification with hypochlorous acid formation. Int J Clin Lab Res 1999;29:155-161.

[52] Panasenko OM, Vakhrusheva T, Tretyakov V, Spalteholz H, Arnhold J. Influence of chloride on modification of unsaturated phosphatidylcholines by the myeloperoxidase/hydrogen peroxide/bromide system. Chem Phys Lipids 2007;149:40-51. 
[53] Dahlgren C, Follin P, Johansson A, Lock R, Orselius K. Localization of the luminol-dependent chemiluminescence reaction in human granulocytes. J Biolumin Chemilumin 1989;4:263-266.

[54] Nurcombe HL, Edwards SW. Role of myeloperoxidase in intracellular and extracellular chemiluminescence of neutrophils. Ann Rheum Dis 1989;48:56-62.

[55] Arnhold J, Hammerschmidt S, Arnold K. Role of functional groups of human plasma and luminol in scavenging of $\mathrm{NaOCl}$ and neutrophil-derived hypochlorous acid. Biochim Biophys Acta 1991;1097:145-151.

[56] Reichl S, Vocks A, Petković M, Schiller J, Arnhold J. The photoprotein Pholasin as a luminescence substrate for detection of superoxide anion radicals and myeloperoxidase activity in stimulated neutrophils. Free Radic Res 2001;35:723-733.

[57] Bizyukin AV, Korkina LG, Velichkovskii BT. Comparative use of 2,7-dichlorofluorescein diacetate, dihydrorhodamine 123, and hydroethidine to study oxidative metabolism in phagocytic cells. Bull Exp Biol Med 1995;119:347-351.

[58] Walrand S, Valeix S, Rodriguez C, Ligot P, Chassagne J, Vasson MP. Flow cytometry study of polymorphonuclear neutrophil oxidative burst: a comparison of three fluorescent probes. Clin Chim Acta 2003;331:103-110.

[59] Gomes A, Fernandes E, Lima JLFC. Fluorescent probes used for the detection of reactive oxygen species. J Biochem Biophys Meth 2005;65:45-80.

[60] Chang CY, Song MJ, Jeon SB, Yoon HE, Lee DK, Kim IH et al. Dual functionality of myeloperoxidase in rotenone-exposed brain-resident immune cells. Am J Pathol 2011;179:964-979.

[61] Mauch L, Lun A, O'Gorman MRG, Harris JS, Schulze I, Zychlinsky A et al. Chronic granulomatous disease (CGD) and complete myeloperoxidase deficiency both yield strongly reduced dihydrorhodamine 123 test signals but can be easily discerned in routine testing for CGD. Clin Chem 2007;53:890-896.

[62] Setsukinai K, Urano Y, Kakinuma K, Majima HJ, Nagano T. Development of novel fluorescence probes that can reliably detect reactive oxygen species and distinguish specific species. J Biol Chem 2003;278:3170-3175.

[63] Shepherd J, Hilderbrand SA, Waterman P, Heinecke JW, Weissleder R, Libby P. A fluorescent probe for the detection of myeloperoxidase activity in atherosclerosis-associated macrophages. Chem Biol 2007;14:1221-1231.

[64] Sun ZN, Liu FQ, Chen Y, Tam PKH, Yang D. A highly specific BODIPY-based fluorescent probe for the detection of hypochlorous acid. Org Lett 2008;10:2171-2174.

[65] Liu SR, Wu SP. Hypochlorous acid turn-on fluorescent probe based on oxidation of diphenyl selenide. Org Lett 2013;15:878-881.

[66] Yang YK, Cho HJ, Lee J, Shin I, Tae J. A rhodamine-hydroxamic acid-based fluorescent probe for hypochlorous acid and its application to biological imagings. Org Lett 2009;11:859-861.

[67] Chen X, Lee KA, Ha EM, Lee KM, Seo YY, Choi HK et al. A specific and sensitive method for detection of hypochlorous acid for the imaging of microbe-induced $\mathrm{HOCl}$ production. Chem Commun 2011;47:4373-4375.

[68] Kenmoku S, Urano Y, Kojima H, Nagano T. Development of a highly specific rhodamine-based fluorescence probe for hypochlorous acid and its application to real-time imaging of phagocytosis. J Am Chem Soc 2007;129:7313-7318. 
[69] Koide Y, Urano Y, Hanaoka K, Terai T, Nagano T. Development of an Si-rhodamine-based farred to near-infrared fluorescence probe selective for hypochlorous acid and its applications for biological imaging. J Am Chem Soc 2011;133:5680-5682.

[70] Nagano T. Bioimaging probes for reactive oxygen species and reactive nitrogen species. J Clin Biochem Nutr 2009;45:111-124.

[71] Yuan L, Lin W, Xie Y, Chen B, Song J. Fluorescent detection of hypochlorous acid from turn-on to FRET-based ratiometry by a HOCl-mediated cyclization reaction. Chem Eur J 2012;18:2700-2706.

[72] Yan Y, Wang S, Liu Z, Wang H, Huang D. CdSe-ZnS quantum dots for selective and sensitive detection and quantification of hypochlorite. Anal Chem 2010;82:9775-9781.

[73] Price M, Reiners JJ, Santiago AM, Kessel D. Monitoring singlet oxygen and hydroxyl radical formation with fluorescent probes during photodynamic therapy. Photochem Photobiol 2009;85:1177-1181.

[74] Martinez VM, de Cremer G, Roeffaers MB, Sliwa M, Baruah M, de Vos DE et al. Exploration of single molecule events in a haloperoxidase and its biomimic. Location of halogenation activity. J Am Chem Soc 2008;130:13192-13193.

[75] Flemmig J, Zschaler J, Remmler J, Arnhold J. The fluorescein-derived dye aminophenyl fluorescein is a suitable tool to detect hypobromous acid ( $\mathrm{HOBr}$ )-producing activity in eosinophils. J Biol Chem 2012;287:27913-27923.

[76] Tanaka K, Miura T, Umezawa N, Urano Y, Kikuchi K, Higuchi T, et al. Rational design of fluorescein-based fluorescence probes. Mechanism-based design of a maximum fluorescence probe for singlet oxygen. J Am Chem Soc 2001;123:2530-2536.

[77] Miura T, Urano Y, Tanaka K, Nagano T, Ohkubo K, Fukuzumi S. Rational design principle for modulating fluorescence properties of fluorescein-based probes by photo-induced electron transfer. J Am Chem Soc 2003;125:8666-8671.

[78] Ueno T, Urano Y, Setsukinai K, Takakusa H, Kojima H, Kikuchi K, et al. Rational principles for modulating fluorescence properties of fluorescein. J Am Chem Soc 2004;126:14079-14085.

[79] Urano Y, Kamiya M, Kanda K, Ueno T, Hirose K, Nagano T. Evolution of fluorescein as a platform for finely tunable fluorescence probes. J Am Chem Soc. 2005;127:4888-4894.

[80] Stelmaszyn'ska T, Zgliczynski JM. N-(2-Oxoacyl)amino acids and nitriles as final products of dipeptide chlorination mediated by the myeloperoxidase $/ \mathrm{H}_{2} \mathrm{O}_{2} / \mathrm{Cl}^{-}$system. Eur J Biochem 1978;92:301-308.

[81] Thomas EL, Grisham MB, Jefferson MM. Preparation and characterization of chloramines. Meth Enzymol 1986;132:569-585.

[82] Coker MSA, Hu WP, Senthilmohan ST, Kettle AJ. Pathways for the decay of organic dichloramines and liberation of antimicrobial chloramine gases. Chem Res Toxicol 2008;21:23342343.

[83] Jakopitsch C, Pirker K, Flemmig J, Hofbauer S, Schlorke D, Furtmüller PG, et al. Mechanisms of reaction of chlorite with mammalian heme peroxidases. J Inorg Biochem 2014;135:10-19.

[84] Pulli B, Ali M, Forghani R, Schob S, Hsieh KLC, Wojtkiewicz G et al. Measuring myeloperoxidase activity in biological samples. Plos One 2013;8:e67976.

[85] Hofbauer S, Gruber C, Pirker K, Sündermann A, Schaffner I, Jakopitsch C et al. Transiently produced hypochlorite is responsible for the irreversible inhibition of chlorite dismutase. Biochemistry 2014;53:3145-3157. 
[86] Hagedoorn PL, de Geus DC, Hagen WR. Spectroscopic characterization and ligand-binding properties of chlorite dismutase from the chlorate respiring bacterial strain GR-1. Eur J Biochem 2002;269:4905-4911.

[87] Flemmig J, Remmler J, Röhring F, Arnhold J. (-)-Epicatechin regenerates the chlorinating activity of myeloperoxidase in vitro and in neutrophilic granulocytes. J Inorg Biochem 2014;130:8491.

[88] Flemmig J, Schwarz P, Bäcker I, Leichsenring A, Lange F, Arnhold J. Rapid and reliable determination of the halogenating peroxidase activity in blood samples. J Immunol Meth 2014;415:45-56.

[89] Kutter D. Prevalence of myeloperoxidase deficiency: population studies using BayerTechnicon automated hematology. J Mol Med 1998;76:669-675.

[90] Kutter D, Devaquet P, Vanderstocken G, Paulus JM, Marchal V, Gothot A. Consequences of total and subtotal myeloperoxidase deficiency: risk or benefit? Acta Haematol 2000;104:10-15.

[91] Nakazato T, Sagawa M, Yamato K, Xian M, Yamamoto T, Suematsu M et al. Myeloperoxidase is a key regulator of oxidative stress-mediated apoptosis in myeloid leukemic cells. Clin Cancer Res 2007;13:5436-5445. 
Table I. Redox properties of hypohalous acids and hypothiocyanite

\begin{tabular}{llll}
\hline & & $E^{\circ}\left(\mathrm{HOX} / \mathrm{X}^{-}, \mathrm{H}_{2} \mathrm{O}\right)$ & $\begin{array}{l}\text { Formation at } \\
\text { Oxidized form }\end{array}$ \\
\hline $\mathrm{pOCl} K_{\mathrm{a}}$ value & at $\mathrm{pH} 7$ and $25^{\circ} \mathrm{C}^{\mathrm{a}}$ & $\mathrm{pH}$ by \\
$\mathrm{HOBr}$ & $7.53^{\mathrm{b}}$ & $1.28 \mathrm{~V}$ & MPO \\
OSCN & $8.8^{\mathrm{c}}$ & $1.13 \mathrm{~V}$ & MPO, EPO \\
\hline
\end{tabular}

${ }^{\mathrm{a} X}$ denotes the corresponding (pseudo)halide form, for details see [22];

bat $25^{\circ} \mathrm{C}$ [23];

cat $25^{\circ} \mathrm{C}[24]$;

dat $25^{\circ} \mathrm{C}[25]$.

Table II. Common substrates for the detection of $\mathrm{HOCl}$ and $\mathrm{HOBr}$

\begin{tabular}{|c|c|c|c|}
\hline Substrate & $\begin{array}{l}\text { HOCl-induced } \\
\text { conversions }\end{array}$ & $\begin{array}{l}\text { Conversions } \\
\text { by } \mathrm{HOBr}\end{array}$ & Remarks \\
\hline Taurine & $\begin{array}{l}\text { Formation of taurine } \\
\text { chloramine [31] }\end{array}$ & $\begin{array}{l}\text { Formation of } \\
\text { taurine } \\
\text { bromamine [32] }\end{array}$ & $\begin{array}{l}\text { Both haloamines can } \\
\text { be differentiated by } \\
\text { their reaction with } \\
3,3^{\prime}, 5,5^{\prime} \text { - } \\
\text { tetramethylbenzidine } \\
\text { in the presence of } \mathrm{I}^{-} \\
{[32]}\end{array}$ \\
\hline MDM & $\begin{array}{l}\text { Formation of } \\
\text { dichlorodimedon [33] }\end{array}$ & $\begin{array}{l}\text { Bromination of } \\
\text { MDM [33] }\end{array}$ & $\begin{array}{l}\text { MDM is also oxidized } \\
\text { by MPO compound I } \\
\text { [34] }\end{array}$ \\
\hline Tyrosine & $\begin{array}{l}\text { Formation of } \\
\text { 3-chlorotyrosine and } \\
3,5 \text {-dichlorotyrosine } \\
{[35,36]}\end{array}$ & $\begin{array}{l}\text { Formation of } \\
\text { 3-bromotyrosine } \\
\text { [37] }\end{array}$ & \\
\hline TNB & $\begin{array}{l}\text { Oxidation to the } \\
\text { colorless } \\
5,5^{\prime} \text {-dithiobis(2- } \\
\text { nitrobenzoic acid) } \\
\text { (DTNB) [38] }\end{array}$ & $\begin{array}{l}\text { HOBr oxidizes TNB } \\
\text { to DTNB [39] }\end{array}$ & $\begin{array}{l}\text { Unspecific oxidation by } \\
\text { other oxidants }[40,41]\end{array}$ \\
\hline Hydroethidine (HE) & $\begin{array}{l}\text { Formation of 2- } \\
\text { chloroethidium [42] }\end{array}$ & & $\begin{array}{l}\text { HE is also oxidized by } \\
\text { other strong oxidants } \\
\text { [43] }\end{array}$ \\
\hline $\begin{array}{l}\text { Unsaturated } \\
\text { phosphatidylcholines }\end{array}$ & $\begin{array}{l}\text { Formation of } \\
\text { chlorohydrins }[44,45]\end{array}$ & $\begin{array}{l}\text { Formation of } \\
\text { bromohydrins [46] }\end{array}$ & $\begin{array}{l}\text { No reaction with } \mathrm{OSCN} \\
{[47]}\end{array}$ \\
\hline
\end{tabular}


Table III. Fluorogenic substrates for assessment of the chlorinating activity in leukocytes

\begin{tabular}{|c|c|c|}
\hline Substrate & Measuring principle & References \\
\hline APF & $\begin{array}{l}\text { Formation of fluorescein from non-fluorescent APF } \\
\text { after cleavage of the } 4 \text {-aminophenyl moiety }\end{array}$ & {$[62]$} \\
\hline $\begin{array}{l}\text { sulphonaphtho-APF } \\
\text { (SNAPF) }\end{array}$ & $\begin{array}{l}\text { Formation of a fluorescent product from non- } \\
\text { fluorescent SNAPF after cleavage of the } \\
\text { 4-aminophenyl moiety }\end{array}$ & {$[63]$} \\
\hline HKOC-1 & $\begin{array}{l}\text { Formation of a fluorescent product upon oxidation } \\
\text { of the } p \text {-methoxyphenol moiety of the BODIPY- } \\
\text { based dye HKOC- } 1\end{array}$ & {$[64]$} \\
\hline HCSe & $\begin{array}{l}\text { Formation of a fluorescent product upon oxidation } \\
\text { of the selenium-containing BODIPY-based dye } \\
\text { HCSe }\end{array}$ & {$[65]$} \\
\hline Rhodamine 19 & $\begin{array}{l}\text { Formation of rhodamine } 19 \text { from a non-fluorescent } \\
\text { spyrocyclic rhodamine derivative }\end{array}$ & {$[66]$} \\
\hline Rhodamine 19-S (R19-S) & $\begin{array}{l}\text { Formation of rhodamine } 19 \text { from spyrocyclic } \\
\text { sulfur-containing non-fluorescent R19-S }\end{array}$ & {$[67]$} \\
\hline HySOx & $\begin{array}{l}\text { Conversion of the non-fluorescent spyrocyclic } \\
\text { sulfur-containing tetramethylrhodamine derivative } \\
\text { HySOx into a fluorescent product }\end{array}$ & {$[68,69]$} \\
\hline MMSIR derivatives & $\begin{array}{l}\text { Formation of a fluorescent product from non- } \\
\text { fluorescent spyrocyclic silicon rhodamine }\end{array}$ & {$[69,70]$} \\
\hline $\begin{array}{l}\text { Rhodamine- } \\
\text { thiosemicarbazides }\end{array}$ & $\begin{array}{l}\text { Cyclization to rhodamine-oxadizoles, FRET-based } \\
\text { mechanism }\end{array}$ & {$[71]$} \\
\hline $\begin{array}{l}\text { Carboxylate coating } \\
\text { CdSe-ZnS quantum dots }\end{array}$ & Fluorescence quenching of quantum dots by $\mathrm{HOCl}$ & {$[72]$} \\
\hline
\end{tabular}


Figures 1-3

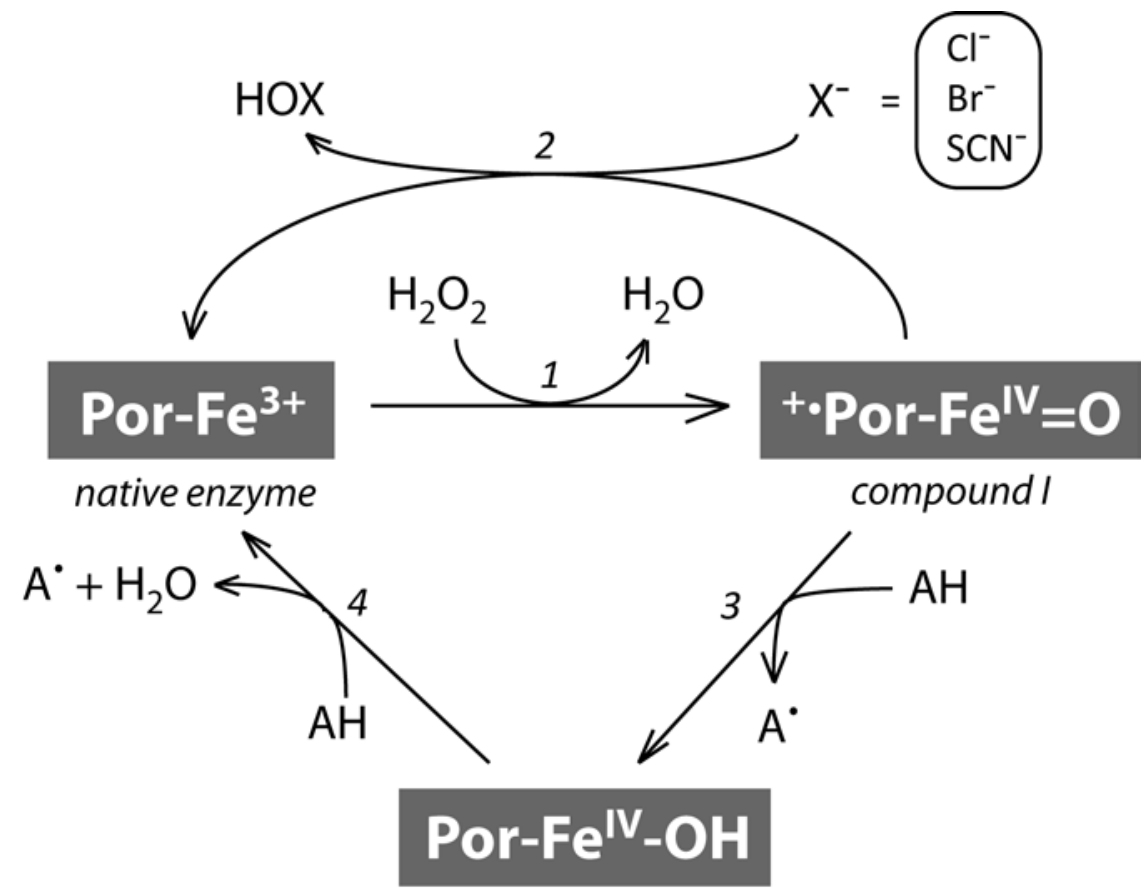

compound II

Figure 1. Halogenation (reactions 1 and 2) and peroxidase cycle (reactions 1, 3, and 4) of heme peroxidases. Por-Fe denotes the porphyrin-iron complex. Further explanations are given in the text. 
Cleavage of a functional moiety abolishes fluorescence quenching of the parent molecule<smiles>[X]Oc1ccc(N)cc1</smiles>

X: fluorescein in APF [62] sulfonaphthofluorescein in SNAPF [63]

Oxidation of a functional residue abolishes quenching of the core fluorophor<smiles>[Y]C1=CC(=O)C=CC1=O</smiles>

Oxidation of a functional residue and ring opening in spyrocyclic non-fluorescent rhodamine derivatives<smiles>[R]c1cc2c(cc1[R])C1(c3cc([R])c([R])cc3O2)c2ccccc2C(=O)N1O</smiles><smiles></smiles>

rhodamine $19[66]$<smiles>[R]c1cc2c(cc1[R])C1(SC(=O)c3cc([R])c([R])cc31)c1cc([R])c([R])cc1O2</smiles><smiles>CCCC</smiles><smiles></smiles>

Figure 2. Main principles and examples for $\mathrm{HOCl}$-mediated conversion of non-fluorescent dyes into fluorophores 


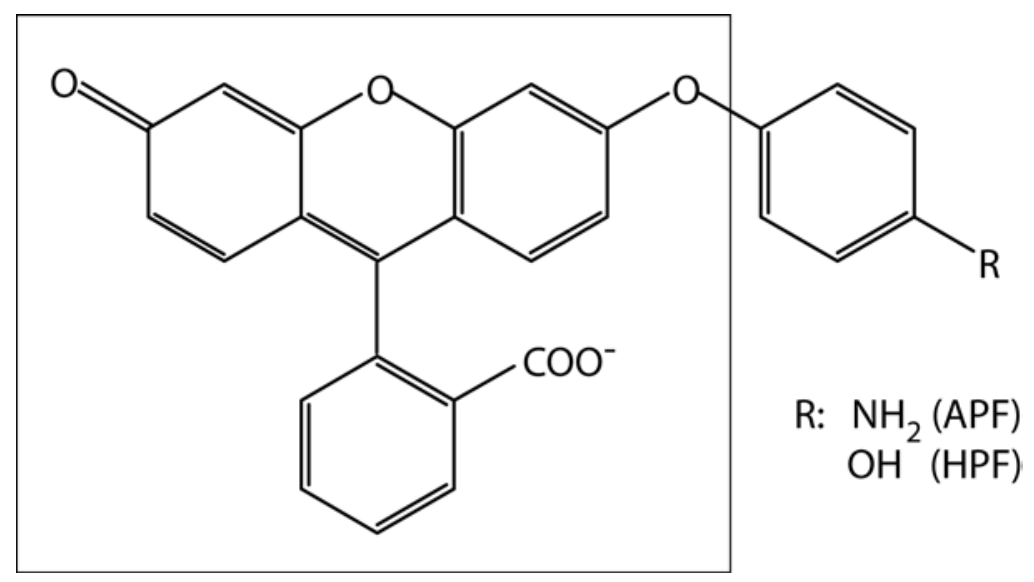

Figure 3. Chemical structures of the fluorescein derivatives APF and HPF. The core fluorescein molecule is highlighted by the rectangle. 